\title{
Erratum to: Breast milk fat concentration and fatty acid pattern during the first six months in exclusively breastfeeding Greek women
}

\author{
Angeliki Antonakou ${ }^{1} \cdot$ Katerina P. Skenderi $^{1} \cdot$ Antonia Chiou $^{1} \cdot$ \\ Constantinos A. Anastasiou ${ }^{1} \cdot$ Chryssa Bakoula $^{2} \cdot$ Antonia-Leda Matalas $^{1}$
}

Published online: 14 July 2016

(C) Springer-Verlag Berlin Heidelberg 2016

\section{Erratum to: Eur J Nutr (2013) 52:963-973 \\ DOI 10.1007/s00394-012-0403-8}

In Table 3 of the original version of this article, there is an error in line 19: By mistake, C22:1 $\omega 9$ is recorded as cis-13,16-docosadienoic acid, while it should have been recorded as cis-13-docosenoic acid. This mistake does not interfere with any of the fatty acids sums or proportions recorded, and it is not found anywhere else in the text or the tables.

The online version of the original article can be found under doi:10.1007/s00394-012-0403-8.

Angeliki Antonakou

a.anton@ hua.gr

1 Present Address: Department of the Science of DieteticsNutrition, Harokopio University of Athens, El. Benizelou 70, 17671 Athens, Greece

2 Present Address: 1st Department of Paediatrics, Children's Hospital "Agia Sophia", Medical School, University of Athens, Thivon \& Papadiamantopoulou, 11527 Athens, Greece 